\title{
Saudação ao Professor José Luiz de Lima Filho na sua posse na Academia Pernambucana de Medicina em 2019*
}

\author{
* Esta saudaçãofoi proferida por Marcelo Moraes Valença na Academia Pernambucana de Medicina em 22 de \\ janeiro de 2019.
}

Meu caro e estimado amigo José Luiz de Lima Filho, Zé Luiz, como é chamado pelos mais próximos.

Foi com muita alegria e honra que recebi a incumbência de proferir hoje a saudação de posse e boas vindas em seu momento de ingresso na Academia Pernambucana de Medicina e lhe felicitar nesta sua nova missão de ser o novo embaixador da APM na missão de:

a) Contribuir para o desenvolvimento e o progresso da Medicina e ciências afins;

b) Incentivar o aprimoramento da cultura médica, da profissão, da ética, do ensino médico e particularmente da medicina social;

c) Colaborar com os poderes públicos e instituições médicas;

d) Promover e estimular a realização de congressos, jornadas, cursos, conferências e debates de interesse cultural, científico, de ensino e médico-social; e

e) Preservar a memória médica. Todos esses são os objetivos pelos quais membros da APM tentam honrar a confraria.

Nesta Casa, fundada há quase 50 anos, entraram apenas 120 acadêmicos entre os mais de 20 mil médicos que trabalharam no estado de Pernambuco no último século. Só da UFPE, instituição onde você exerce brilhantemente a função de professor para alunos do curso de Medicina, foram 10 mil médicos formados desde a inauguração da Faculdade de Medicina em 1920, cuja primeira sede foi construída de 1925 a 1927, neste magnífico prédio que estamos agora - por isso denominado Memorial da Medicina de Pernambuco.

Vale a pena registrar que em 28 de fevereiro de 1950 professores da nossa Universidade fundaram outra Escola de Medicina no Estado de Pernambuco, a Faculdade de Ciências Médicas de Pernambuco.
Com sede bem próxima de onde estamos agora, no outro lado do rio Capibaribe, no casaram numero 198, rua Benfica, na Madalena, hoje Batalhão Mathias de Albuquerque, onde também outros milhares de médicos se formaram. Por isso eu considero as duas escolas como coirmãs. A grande maioria dos acadêmicos titulares da APM se formou em uma das duas escolas de Medicina.

A Academia Pernambucana de Medicina, que tem 50 cadeiras de acadêmicos titulares, numeradas de 1 a 50, foi criada no dia 17 de dezembro de 1970, pelo visionário e nosso grande Professor Fernando Jorge Simão dos Santos Figueira, na época Presidente da Sociedade de Medicina de Pernambuco, hoje Associação Médica de Pernambuco.

As vagas só ocorrem por falecimento de acadêmico fundador ou titular, e são preenchidas de acordo com as normas estatutárias e regimentais que falaremos adiante, por eleição em escrutínio secreto da Assembléia.

$\mathrm{O}$ candidato a membro titular deve ter um destaque na atividade profissional; sobressair no campo da cultura geral; ter distinção em atividades universitárias e de pesquisa; ter também distinção em atividades filantrópicas e sociais; sobressaindo na prestação de benefícios notáveis à coletividade; e que reconhecidamente se distinguiu no campo da memória médica; e acima de tudo se conduziu com inteireza moral.

E acreditem, nem todos que se candidataram foram aprovados no escrutínio secreto.

Segundo o meu amigo Luiz de Gonzaga Braga Barreto, médico, confrade e grande historiador, um dos maiores responsáveis pelo crescente sucesso da nossa Academia de Medicina pelo brilhantismo de seus atos, em 1978 depois da saído do Colégio Militar, que ficou sediado neste prédio, a Universidade Federal de Pernambuco e a Academia Pernambucana de Medicina fizeram um convênio 
assinado pelo Reitor Paulo Maciel e o Professor Fernando Figueira em que eram cedidos à Academia o prédio da Faculdade de Medicina do Recife e o do Serviço de Verificação de Óbitos (IAB) para serem usados pela Academia. Esse convênio foi renovado por várias vezes. Infelizmente, no tempo do Reitor Ednado Bastos o convênio ficou sustado pois havia uma demanda das entidades médicas lideradas pela Academia Pernambucana de Medicina solicitando que o prédio fosse restaurado pois eram precárias as condições, por outra parte a UFPE nutria o entendimento que o prédio fosse alienado pela Universidade tendo havido inclusive pedido aprovado pelo MEC para essa venda.

Uma ampla manifestação das entidades médicas foram contrária a essa decisão de venda da Memória da Medicina Pernambucana e porque não dizer do Nordeste, com grandes repercussões. Essa peleja demorou-se até o início da administração do Reitor Éfrem Maranhão que resolveu requalificar todas as estrutura dos dois edifícios. O Reitor criou uma comissão cujo presidente foi Dr. Bertoldo Kruse, então pro-reitor de planejamento da UFPE, que era constituída pelo diretor do Centro de Ciências da Saúde e cada um dos representantes de cada uma das sete instituições culturais que aqui já funcionavam desde o primeiro convênio da Academia com a UFPE. O prédio requalificado foi inaugurado em novembro de 1995 sob o nome de Memorial da Medicina de Pernambuco sugerido pela Academia de Medicina, cabendo ao Dr. Veloso Costa essa designação que foi aprovado pela Universidade $\mathrm{e}$ colocado no frontispício do prédio como ainda se mantém. $\mathrm{O}$ prédio foi inaugurado para o uso autorizado das 7 instituições culturais, literárias e científicas que aqui funcionam, entre elas o Instituto Pernambucano da História da Medicina e seu Museu da Medicina, Associação Brasileira dos Médicos Escritores e a Associação dos Ex-Alunos. Isso tudo capitaneado pela APM. Registro agora este fato para lembrar da importância da APM para a missão cultural, científica e política da nossa Academia que muito representa a própria UFPE.

$\mathrm{Eu}$ percebo que entre os que ingressaram na APM podemos classificar os acadêmicos em 3 grupos principais: aqueles que se descaram na gestão e tiveram impacto em políticas públicas. Oito dos membros da APM já foram secretários da Saúde no Estado ou na cidade do Recife. Professores que criaram grandes escolas nas suas especialidades, com formação de gerações de médicos. E um pequeno grupo que se destacou na produção científica, com inserção internacional de destaque.

Não é uma tarefa tão simples na sua obviedade elaborar um discurso de saudação revelando toda uma história de vida e conquistas que o nosso protagonista construiu, talvez nem imaginada na infância, pela grandeza que assumiu nos dias atuais. E todos aqui sabem, caro Zé Luiz, que esse caminho escolhido por você ainda é longo pelo potencial enorme de grandes saltos no universo científico futuro.

Impossível imaginar ouvindo minhas palavras toda a amplitude de uma vida de sucesso como a sua. Desculpe-me antecipadamente, porque sei que muito não será dito.

Em 24 de setembro de 1960 nasceu José Luiz de Lima Filho, filho de Dona Irene e Seu Lima, pais trabalhadores que participaram ativamente da educação dos filhos pelo exemplo de dignidade, apesar de condições financeiras limitadas. Mostraram o caminho da educação, e mesmo estudando em colégios públicos (entre eles o Ginásio Pernambucano) Zé Luiz conseguiu bolsa de estudo para estudar para o vestibular, passando entre os primeiros colocados no curso de Medicina da UFPE em 1978.

O Professor José Luiz formou-se em Medicina na Universidade Federal de Pernambuco em 1983 e recebeu o título de doutor em Bioquímica e Microbiologia pela University of St Andrews, Escócia, em 1987. Realizou pós-doutoramento na Alemanha (GBF), no Japão (Instituto de Tecnologia de Tóquio) e nos Estados Unidos (National Institute Of Standard And Technology, NIST) na área de diagnóstico e desenvolvimento de biossensores.

Consultor de várias instituições, entre elas FAPERJ, FACEPE, FAPEMIG, FINEP, CAPES, MCTI, FIOCRUZ, FAPEMA e CNPq.

Faz parte do corpo editorial de várias revistas científicas internacionais, como o World Jornal of Microbiology and Biotechnology, FITOS e Journal of Applied Oral Science. Trabalha como referee (avaliador dos artigos submetidos) da Analytica Chimica Acta, Food Science, Brazilian Journal of Microbiology, Materials Science \& Engineering, International Journal of the Physical Sciences, African Journal of Food Science, Human Immunology, Process Biochemistry, Biosensor Letters, Scientific Research and Essays, Polymer 
International, Enzyme Research e Bioresource Tecchnology, filtrando os bons artigos e sugerindo alterações para melhorar a publicação para que a comunidade científica tenha melhor proveito. Esse trabalho invisível dos avaliadores é de extrema importância para a Ciência, valorizando estudos que frequentemente levaram anos para serem realizados até serem resumidos em poucas páginas publicadas em um grande jornal.

Teve o privilégio de durante seis anos ser membro da Comissão Técnica Nacional de Biossegurança (CTNBIO). Possui experiência na área de Microbiologia, com ênfase em Microbiologia Industrial e de Fermentação, e na área de instrumentação e processos biológicos, atua principalmente nos temas: biosensor, enzimologia, câncer, doenças metabólicas e biotecnologia.

Atualmente é Professor Titular de Bioquímica da Universidade Federal de Pernambuco desde julho de 2011 e Diretor científico do Laboratório de Imunopatologia Keizo Asami - LIKA da Universidade Federal de Pernambuco, desde 2000.

Em 2010 foi agraciado com o titulo GRÃ-CRUZ da ordem Nacional do Mérito Científico, foram poucos os cientistas que já receberam tal comenda.

Mesmo antes de ingressar como docente da UFPE já orientava a pesquisas de alunos de iniciação científica e mestrandos nas áreas de instrumentação e processos fermentativos. Alunos que hoje, são professores de universidades como a própria UFPE, UFRPE, UNICAMP e, acreditem, Johns Hopkins University e Harvard University, para não falar de outras tantas.

Em 1997 o reitor convidou Zé Luiz para a Diretoria de Desenvolvimento da PROACAD, cargo associado a criação das normas dos cursos de graduação.

No período de 2003 a 2008 o Zé Luiz foi conselheiro da Câmara técnica do CREMEPE na área de informática em saúde. Este convite foi realizado devido aos trabalhos desenvolvido no LIKA e no HC.

Como representante da CTNBIO participou da comissão para regulamentar estudos no Brasil com o uso de células tronco, colocando o Brasil no mapa do mundo nesta área de pesquisa.
Após quinze anos à frente do LIKA, depois de ganhar prêmios internacionais e nacionais, de ter formado mais de 100 mestres e doutores, ter tido mais de 200 alunos de iniciação, e ter publicado mais de 200 "papers" o Zé Luiz foi reconduzido a direção do LIKA, desta vez pelo Magnifico Reitor Anisio Brasileiro de Freitas Dourado.

$\mathrm{Na}$ faculdade de medicina foi logo envolvido pelo ambiente da ciência no Departamento de Bioquímica após uma aula sobre segundo mensageiro - AMP cíclico. O que levou Zé Luiz a procurar o Professor Luiz Carvalho, que o apresentou ao Professor William McDonald Ledingham (Professor Escocês visitante da Universidade de St. Andrews) que estava participando do curso de mestrado no Departamento de Bioquímica. Em 1983, o Zé Luiz foi convidado a realizar o doutorado na Universidade de St. Andrews - Escócia, para ser orientado pelo Professor Ledingham. Ele aceitou, e iniciou os estudos em 1984, finalizando em 1987.

Aliás, o grande Professor Luiz Carvalho em muito influenciou a carreira do seu discípulo José Luiz, tornando o caminha mais fácil para em poucos anos torná-lo cientista com inserção internacional. "Zé Luiz nasceu cientificamente num ambiente adequado - o Departamento de Bioquímica." São palavras do Professor Luiz Carvalho.

Ainda palavras do Professor Luiz Carvalho: "Os pesquisadores ativos e competentes da UFPE nos dias de hoje muito devem aos seus antecessores que em condições muito adversas souberam montar a estrutura com a qual nos beneficiamos. Devemos e eles muita reverência. Sem esses pioneiros não existiríamos. Contemplar suas contribuições com a qualidade das nossas pode parecer tarefa menor, mas há que se ver os contextos em que elas foram produzidas. Alguns dos nossos antecessores fundaram escolas, entendidas aqui como a transmissão de uma cultura às novas gerações. Lamento a abolição da cátedra, quando esses iluminados lideravam escolas. Professor Doutor José Luiz de Lima Filho assume a cadeira de número 29 que tem como patrono o Professor Doutor Aggeu Sérgio de Godoy Magalhães e foi ocupada previamente pelo Professor Doutor Ageu de G. Magalhães Filho. Estes dois, pai e filho, muito contribuíram para a ciência médica pernambucana."

Pedi também ao Professor Luiz Carvalho uma ajuda para registrar alguns nomes de professores da UFPE 
que serviram para criar um núcleo cientifico de destaque à UFPE, que antecederam a chegada do Professor José Luiz no Departamento de Bioquímica em 1989 como docente.

Prof. Marcionilo Lins era o Catedrático na época. Visionário, fomentou as pesquisas em Ciência e $\quad$ Tecnologia.

A Ciência na então Faculdade de Medicina da UFPE se iniciou não somente na Bioquímica, mas em outros Departamentos, como:

Na área

básica:

Prof. Nelson Chaves no Departamento de Fisiologia; registre-se aqui a relevância da Profa. Naíde Teodósio em sua equipe. Prof. Aluízio Bezerra Coutinho no Departamento de Patologia Geral;

Prof. Antonio Zappalá no Departamento de Anatomia e membro da ANM (Cadeira 81)

Na clínica:

Prof. Salomão Kelner - cirurgia. Prof. Amaury Coutinho - clinica médica. Prof. Fernando Figueira - na pediatria. Prof. Jorge Lobo - na dermatologia. Prof. Romero de Gama Marques Prof. Ruy João Marques que ocupou a cadeira número 12 da Academia Nacional de Medicina. Prof. Luiz Tavares da Silva - na cirurgia cardiovascular.

Prof. Luiz Ignácio De Barros Lima - na ortopedia.

Prof. Frederico Simões Barbosa

na epidemiologia e Saúde pública.

Prof. Manoel Caetano de Barros

Prof. Wilson Farias na neurologia.

Só para lembrar alguns.

Seu primeiro trabalho foi com manipueira envolvendo o Professor Bill Ledingham e o Professor Marcionilo Lins, o então chefe do Departamento de Bioquímica e ex-reitor da UFPE.

Hoje vi no seu Lattes que foram publicados 259 artigos científicos, a grande maioria em revista internacionais de grande circulação nos meios científicos. Orientou 40 dissertações de Mestrado e
50 teses de Doutorado. Foram 6 as supervisões de pós-doutorado. Registrou 13 patentes. Continua muito ativo em suas orientações com muitos alunos de mestrado, doutorado e pós-doutorado, sem mencionar os da graduação.

Se você resolvesse parar hoje sua atividade docenteacadêmica e de gestor eu afirmaria que o seu legado para a UFPE é incomensurável e infinito, vai continuar por décadas, de geração em geração, se multiplicando numa velocidade exponencial semelhante ao que ocorre na produção de conhecimentos.

Meu caro Zé Luiz, sinta-se muito bem-vindo entre nós! 